\title{
Numerical methodology for determining the soil mass surface slump, caused by the tunnel construction with the geodetic monitoring results comparison
}

\author{
Sergei Kositsyn and Vladimir Akulich* \\ Russian University of Transport, 127994, GSP-4, Moscow, Russia
}

\begin{abstract}
The work is aimed at determining the construction effect of a running tunnel on the stress-strain state change of the surrounding soil massif, in particular, on the development of a sediment basin on the Earth's surface. The soil massif is defined by an elastoplastic material according to the Drucker - Prager model. The paper proposes two numerical methods for solving the problem: with and without the use of contact elements for modeling the construction gap between the tunnel shell and the soil mass caused by the tunnel boring mechanized complex operation. The proposed methods were applied in the construction of Kalininsko-Solntsevskaya line tunnels of the Moscow subway. A comparative analysis of the results obtained with geodetic monitoring of the Earth's surface slump in the construction influence zone has been carried out.
\end{abstract}

\section{Introduction}

Currently, in modern underground construction, the issue of a mechanized tunnel boring complex impact (TBM tunneling) on the subsidence of the Earth's surface during tunneling is relevant. The task of this work is to develop a numerical method that makes it possible to determine the change in the stress-strain state (SSS) soil massif, in particular to determine the slump of the Earth's surface caused by the TBM tunneling work.

In the course of TBM tunneling construction work (shield driving), the soil is displaced into the bottom of the tunnel in those areas where the tunnel is not fixed or partially fixed. In this regard, more soil is removed from the underground space than that calculated in the project. This extra rock volume is called "lost volume". Parameter $V$ characterizes the "lost volume" and is determined by the excavated rock volume ratio to the design volume of the tunnel. "Lost volume" is a measure of the array disturbance by TBM tunneling work and causes the formation of a trough of subsidence of the Earth's surface.

The developed numerical technique should allow taking into account the additional "lost volume" of the rock in the course of the work TBM tunneling, which is the main cause of subsidence of the Earth's surface. The numerical technique was developed in the finite

\footnotetext{
* Corresponding author: vladimir.akulich@gmail.com
} 
element software complex MSC PATRAN - NASTRAN in a constructively nonlinear problem formulation.

\section{Two numerical methods for determining the subsidence of the Earth's surface in the course of TBM tunneling work in the spatial problem setting}

The MSC PATRAN - NASTRAN software package is based on the finite element method, which allows mathematical modeling of the processes occurring in the soil massif [1,2].

First, the system "cylindrical shell - surrounding massif" was modeled, which approximates one of the four projected subway tunnels, for a comparative analysis of the results obtained with the known analytical semi-empirical methods.

An isotropic volumetric array modeling soil is represented by three-dimensional finite elements in the form of eight-node parallelepipeds. The tunnel shell is approximated by two-dimensional flat four-node elements [3].

The load from the dead weight of the soil and the tunnel is applied to the design model. The lateral and lower boundaries of the soil massif are fixed from displacements along the normals to the surfaces. The shell at the ends has similar support fixings, which ensure the geometric invariability of the design model. The shell material is assumed to be unlimitedly linearly elastic. The material of the soil massif is specified by the Drucker - Prager elastoplastic model. Table 1 shows the main physical and mechanical soil properties $[4,5]$.

Table 1. The main physical and mechanical soil properties

\begin{tabular}{|c|c|c|c|c|c|c|}
\hline No. & $\begin{array}{c}\text { Soil } \\
\text { description }\end{array}$ & $\begin{array}{c}\text { Density, } \\
{\left[\mathrm{kg} / \mathrm{m}^{3}\right]}\end{array}$ & $\begin{array}{c}\text { Poisson's } \\
\text { ratio } v\end{array}$ & $\begin{array}{c}\text { Deformation } \\
\text { modulus } E, \\
{[\mathrm{MPa}]}\end{array}$ & $\begin{array}{c}\text { Specific } \\
\text { adhesion } \\
C,[\mathrm{kPa}]\end{array}$ & $\begin{array}{c}\text { Internal } \\
\text { corner } \\
\text { friction } \\
\varphi, \\
{[\text { degree }]}\end{array}$ \\
\hline 1 & Filled soil & 1920 & 0.30 & 13 & 15 & 13 \\
\hline 2 & $\begin{array}{c}\text { Powdery } \\
\text { loams }\end{array}$ & 2080 & 0.37 & 22 & 33 & 21 \\
\hline 3 & Sandy loam & 2160 & 0.35 & 27 & 45 & 23 \\
\hline 4 & Sandy loam & 2120 & 0.35 & 27 & 46 & 24 \\
\hline 5 & $\begin{array}{c}\text { Powdery } \\
\text { sands }\end{array}$ & 2000 & 0.31 & 30 & 6 & 33 \\
\hline 6 & Fine sands & 2010 & 0.30 & 33 & 4 & 34 \\
\hline
\end{tabular}

The physical and mechanical properties of the tunnel shell were taken as for reinforced concrete B45. The geometry of the lining ring of the running tunnel was taken according to the standard design: outer diameter $-5800 \mathrm{~mm}$; inner diameter $-5300 \mathrm{~mm}$; the average length of the lining ring along the tunnel $-1400 \mathrm{~mm}$; block thickness $-250 \mathrm{~mm}$.

According to the calculation results, it should be noted that when modeling the gap according to the "node-to-node" principle without the use of contact elements, the calculation model works improbably, and the field of vertical displacements of the soil massif does not correspond to reality: the upper surface of the massif experiences a rise. This is explained by the fact that the weight of the remote part of the massif is greater than the weight of the mounted tunnel shell, which causes the unloading of the underlying layers of the soil massif and the lifting of the massifupper surface.

To solve the above-mentioned problem, it is proposed to model the gap between the tunnel shell and the soil mass in two ways: three-dimensional finite elements with low 
deformation characteristics and one-dimensional contact elements $[6,7,8]$. The stiffnesses of the contact elements tended to zero in tension and to infinity in compression. The initial clearance of the contact elements was $50 \mathrm{~mm}$.

For the results obtained on the basis of two calculation models, a comparative analysis was carried out, including with the well-known generalized semi-empirical method.

When modeling the gap with three-dimensional elements with low deformation characteristics, the maximum displacement over the axis of the tunnel was $-0.8 \mathrm{~cm}$. When modeling the gap with contact elements, the maximum displacement over the axis of the tunnel was $-1.2 \mathrm{~cm}$ for a constant deformation modulus along the entire perimeter of the tunnel, the gap is not completely closed everywhere, in particular in the tunnel archshell. Also, three-dimensional elements have nonzero tensile stiffness, which does not allow the shell to detach from the soil massif at stretching points.

For a comparative analysis of the results obtained by two numerical methods, the slump trough of the massif surface was calculated according to the generalized semi-empirical method described in $[9,10]$. This subsidence trough is described by the dependence:

$$
S=\frac{V_{S}}{\sqrt{2 \pi i_{x}}} e^{-\frac{x^{2}}{2 i_{x}^{2}}}\left[G\left(\frac{y-y_{i}}{i_{x}}\right)-G\left(\frac{y-x y_{f}}{i_{x}}\right)\right]
$$

where $S$ is the amount of subsidence of the Earth's surface at a point $(x, y) ; x$ defines the distance from the point of interest to the longitudinal axis of the tunnel; $y$ is the point coordinate along the longitudinal axis of the tunnel; $V_{s}$ is auseful volume of the Earth subsidence trough; $y_{i}$ denotes the starting position of the tunnel; $y_{f}$ is aface forehead location; $i_{x}$ is the subsidence trough width, $i_{x}=k Z ; k$ is adimensionless constant characterizing rock parameters; $Z$ is the distance from the ground to the longitudinal axis of the tunnel; $G$ shows distribution function:

$$
G=\frac{1}{\sqrt{2 \pi}} \int_{-\infty}^{\alpha} e^{-\frac{\alpha^{2}}{2}} d \alpha ; \alpha=\frac{y-y_{i}}{i}
$$

The discrepancy between the maximum slump of the massif surface over the shell axis, obtained by the generalized semi-empirical method, with the maximum slump of the computational model with a layer of volumetric finite elements of the gap was $42 \%$, with the maximum slump of the computational model with the contact elements of the gap - $12 \%$. Thus, the best convergence is obtained when using the contact elements of the gap.

Figure 1 shows the field of vertical displacements in the soil mass according to the results of the second stage of calculating the model with contact elements.

After determining the subsidence of the soil massif surface in the direction transverse to the tunnel axis, a computational model was drawn up to determine the subsidence of the soil massif surface in the direction longitudinal to the tunnel axis.

In this computational model, the tunnel shell was modeled for half the soil massif length to study the subsidence of the Earth's surface along the tunnel axis. The gap was modeled by contact elements. The maximum displacement above the axis of the tunnel was $-1.2 \mathrm{~cm}$. The field of vertical displacements of the soil mass along the axis of the tunnel along the entire length of the design model is shown in Figure 2. 


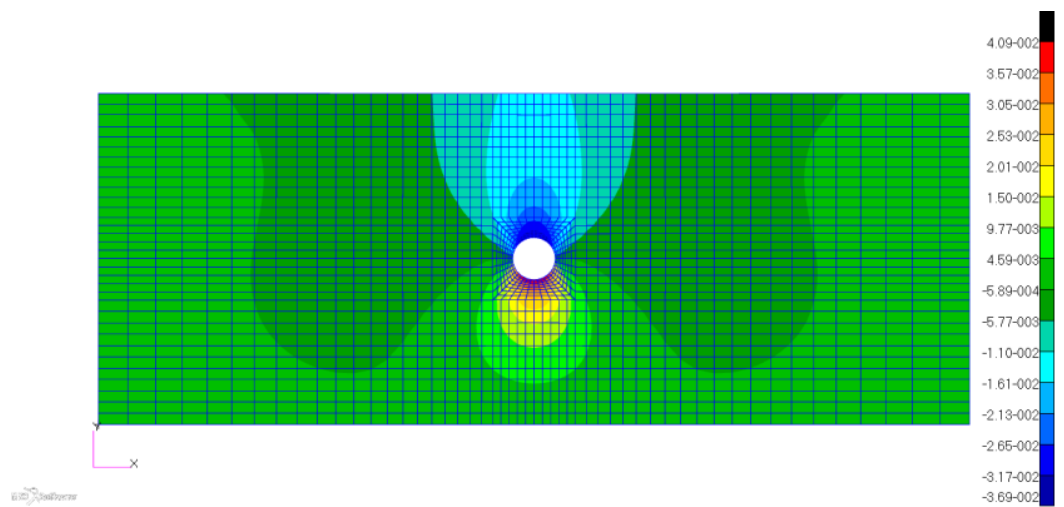

Fig. 1. The field of vertical displacements of the array in the transverse direction to the shell axis of the design model with contact elements of the gap

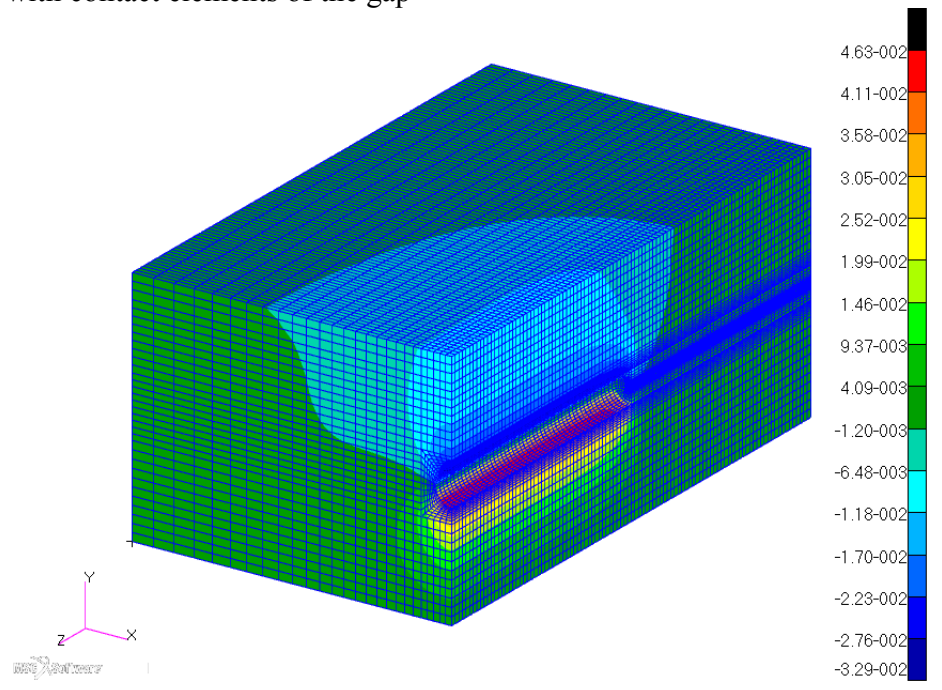

Fig. 2. The field of vertical displacements of the array along the shell axis of the design model with contact elements of the gap

\section{Using the proposed methods for determining the Earth's surface slump during the Kalininsko-Solntsevskaya line construction of the Moscow subway}

The developed methods have received practical application in determining the subsidence trough of a section of the Earth's surface with operated railway tracks located within the zone of influence of the construction of the projected running tunnels of the Kalininsko-Solntsevskaya line of the Moscow subway using TBM tunneling.

Two computational models were compiled using the two methods of accounting for the gap described earlier. Each computational model includes four cylindrical shells at a depth of $22.7 \mathrm{~m}$ from the upper surface of the array, approximating the projected running tunnels, one of which lies at an angle to the axes of the remaining shells in the horizontal plane and $10.3 \mathrm{~m}$ deeper railway track in the form of rail threads, the characteristics of which correspond to the P65 type.

The calculations were made in a constructively nonlinear formulation (contact forces were determined by the method of successive approximations) and were carried out in two 
stages. In the first stage, the initial SSS soil from its own weight (everyday condition); in the second stage, the final soil massif SSS after the installation of the tunnel shells with loads from the own weight of the soil and the tunnel lining weight.

The subsidence of the Earth's surface over the axes of the tunnels, according to the calculation results using two compiled models, are shown in Table 2.

Table 2. The subsidence of the Earth's surface over the axes of the tunnels

\begin{tabular}{|c|c|c|c|c|}
\hline Tunnel, No. & 1 & 2 & 3 & 4 \\
\hline \multicolumn{6}{|c|}{ Modeling a gap with a layer of volumetric elements } \\
\hline $\begin{array}{c}\text { Slump over the } \\
\text { tunnelaxis, [cm] }\end{array}$ & 0.7 & 0.9 & 1.0 & 0.7 \\
\hline \multicolumn{5}{|c|}{ Gap modeling with contact elements } \\
\hline $\begin{array}{c}\text { Slump over the } \\
\text { tunnelaxis, [cm] }\end{array}$ & 1.5 & 2.2 & 2.3 & 1.5 \\
\hline
\end{tabular}

It can be seen from the Table that the slump values of the computational model using the contact elements of the gap exceed the slump values of the model using the gap volumetric finite elements layer by the factor of two. The maximum slump above the shell axis is $2.3 \mathrm{~cm}$ downward. The fields of the array vertical displacements using a layer of volumetric finite elements of the gap and contact elements of the gap are shown in Figures 3 and 4, respectively.

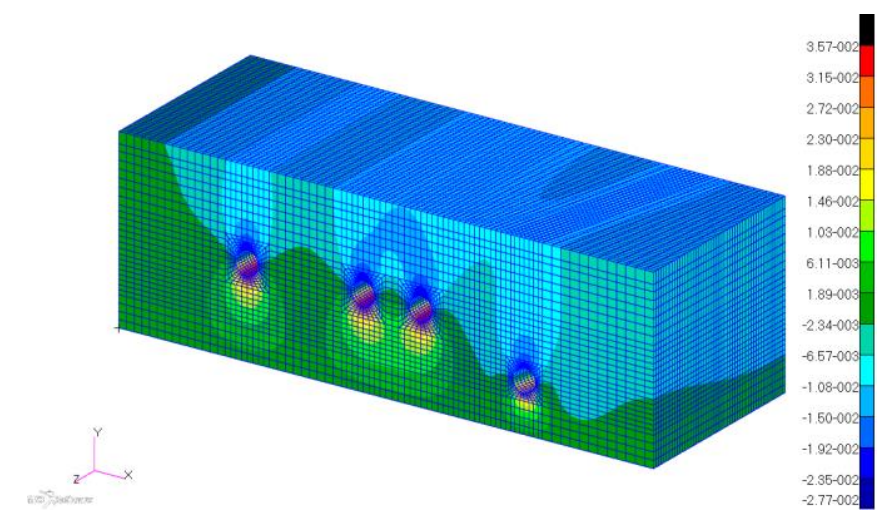

Fig. 3. The field of vertical displacements of the computational model array with a gap volumetric finite elements layer

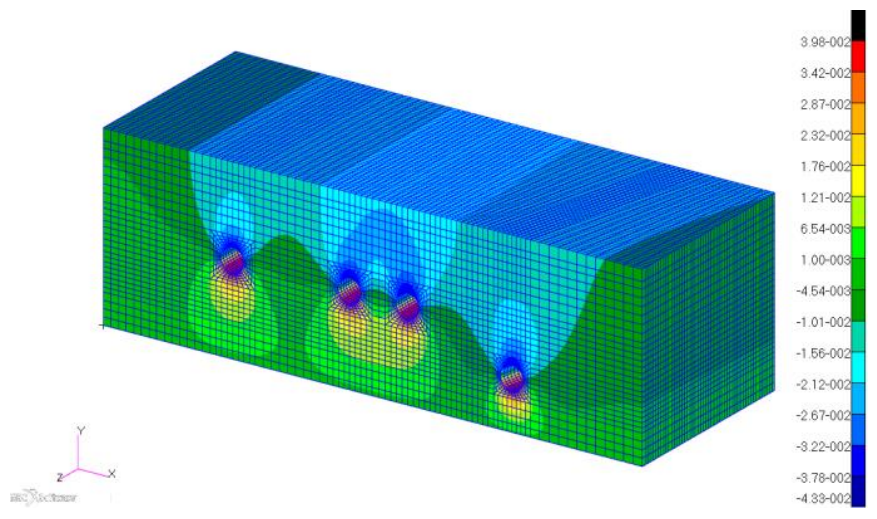

Fig. 4. The field of vertical displacements of the gap computational model array with contact elements 


\section{Comparative analysis with geodetic monitoring}

A comparative analysis of the results obtained with geodetic monitoring of the surface slump in the zone of influence of the construction of the Kalininsko-Solntsevskaya line projected running tunnels of the Moscow subway was carried out. The surface slumps were measured at two points: the existing railway track and the contact network support (located $5 \mathrm{~m}$ from the longitudinal axis of the railway track). Table 3 shows the maximum displacements of the base according to the results of numerical calculations using contact elements of the gap and according to geodetic monitoring data, as well as the difference between them in $\%$.

Table 3. The maximum displacements of the base

\begin{tabular}{|c|c|c|}
\hline Measurement point & Existing railway track & $\begin{array}{c}\text { Contact network } \\
\text { support }\end{array}$ \\
\hline $\begin{array}{c}\text { Numerical calculation, } \\
{[\mathrm{cm}]}\end{array}$ & 2.30 & 2.14 \\
\hline Geodetic monitoring, [cm] & 2.75 & 2.40 \\
\hline Slump difference, $[\%]$ & 16 & 11 \\
\hline
\end{tabular}

Based on the values given in Table 3, it was concluded that the use of contact elements of the gap when determining the slump trough of the array surface in the transverse direction to the shell axis leads to a fairly good convergence with the geodetic monitoring results.

Figure 5 shows the subsidence curve of the massif surface in the transverse direction to the tunnels axes according to the numerical calculations results (line with round markers) and the maximum displacements of the existing railway track (square marker) and the support of the contact network (triangular marker) obtained from geodetic monitoring. A scaled deformed view of the existing track is shown in Figure 6.

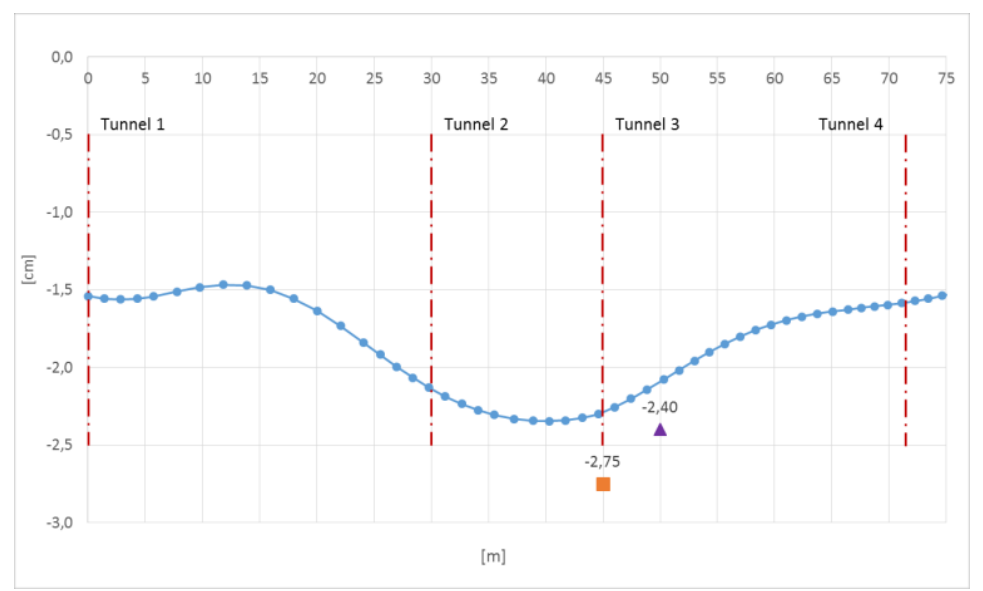

Fig. 5. The surface slump curve according to the numerical calculations results and the maximum displacements of the existing railway track and support of the contact network, obtained from geodetic monitoring 


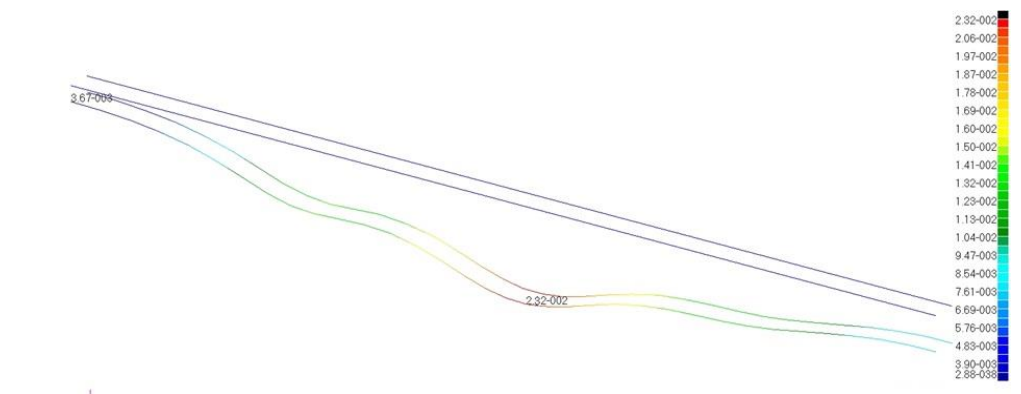

Fig. 6. A scaled deformed view of an existing railway track

\section{Conclusion}

A technique based on spatial computational models using two methods of creating a gap between a cylindrical shell and the surrounding massif, which makes it possible to take into account the "lost volume" of soil from TBM tunneling work has been developed and implemented. At the same time, if we compare the developed design models with each other, then the application of the method with contact elements of the gap more likely describes the volume of additional "lost" soil and gives the results closer to the well-known generalized semi-empirical method.

The proposed methods were tested in the design and construction of the Kalininsko-Solntsevskaya line running tunnels of the Moscow subway. A comparative analysis has been carried out for the maximum displacements of the surface obtained from a numerical calculation using the contact elements of the gap and the results of geodetic monitoring, in which good convergence between them has been revealed.

\section{References}

1. MSC Nastran 2018, Quick Reference Guide, MSC, Software Corporation, 2017.

2. MSC Patran 2016, User's Guide, MSC. Software Corporation, 2016.

3. S.I. Trushin, Theory and tasks (Publishing house ASV, Moscow, 2008).

4. D.G. Shimkovich, FEMAP \& NASTRAN, Engineering analysis by the finite element method (DMK Press, Moscow, 2008).

5. S.B. Kositsyn, D. B. Dolotkazin, Calculation of rod systems interacting with an elastic foundation by the finite element method using the MSC, Nastran for windows software package: tutorial (MIIT, Moscow, 2004).

6. A.N. Leont'ev, I.G. Leontyev, Vestnik MGSU 4, 167 - 172 (2010).

7. N.N. Leont'ev, A.N. Leontyev, D.N. Sobolev, N.N. Anokhin, Fundamentals of the theory of beams and slabs on a deformable foundation: a tutorial (MECU, Moscow, 1982).

8. N.N. Shaposhnikov, Scientific collection of Moscow Institute of Railway Engineers 131, 296 - 305 (1961).

9. P.B. Attewell, J.P. Woodman, Ground Engineering 15 (7), 13 - 22, 36 (1982).

10. R.B. Peck, Deep excavations and tunneling in soft ground, Proc. 7-th ICSMFE (Mexico, 1969). 